\title{
Genetic and physiological diversity of white Spanish broom (Chamaecytisus albus) endophytes*
}

\author{
Karolina Włodarczyk, Sylwia Wdowiak-Wróbel, Monika Marek-Kozaczuk and Jerzy Wielbo ${ }^{\varpi}$ \\ 1Department of Genetics and Microbiology, Faculty of Biology and Biotechnology, Maria Curie-Sklodowska University in Lublin, Lublin, Poland
}

\begin{abstract}
Chamaecytisus albus (Spanish broom) is a legume shrub that can be found in only one natural locality in Poland. This specimen is critically endangered; therefore, different actions focusing on protection of this plant in the natural habitat are undertaken, and one of them involves studies of the population of Chamaecytisus albus bacterial endophytes, which in the future could be used as bioprotectants and/or biofertilizers. A collection of 94 isolates was obtained from Spanish broom nodules, and the physiological and genetic diversity of these strains was studied. A few potentially beneficial traits were detected, i.e. secretion of cellulases (66 isolates), production of siderophores (60 isolates), phosphate solubilization ( 25 isolates), and production of IAA (58 isolates), indole (16 isolates), or HCN (3 isolates). Twenty-nine of the 94 tested isolates were able to induce the development of root nodules in plants grown in vitro and can therefore be assumed as Chamaecytisus albus symbionts. Genome fingerprinting by BOX-PCR, as well as gyrB and nod $Z$ gene sequencing revealed a great genetic diversity of specimens in the collection. The symbiotic isolates were classified in different clades, suggesting they could belong to different species, however, most of them revealed sequence similarity to Bradyrhizobium genus.
\end{abstract}

Key words: Chamaecytisus albus, Spanish broom, endophytes, symbionts

Received: 12 April, 2021; revised: 22 July, 2021; accepted: 26 July, 2021; available on-line: 24 August, 2021

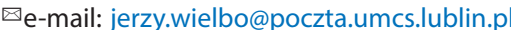

*This paper is dedicated to Professor Wacław Tadeusz Szybalski on the 100th anniversary of his birth

Acknowledgements of Financial Support: This research was financed by the Provincial Fund for Environmental Protection and Water Management in Lublin, title of the project: "The use of rhizobia in biological protection of Chamaecytisus albus".

Abbreviations: CAS, chrome azurol S; CMC, carboxymethylcellulose; IAA, indole-3-acetic acid; UPGMA, unweighted pair group method with arithmetic mean; TCP, tricalcium phosphate

\section{INTRODUCTION}

Rhizobia are soil saprophytic bacteria that can develop a symbiotic relationship with legumes (Fabaceae). In such symbiosis, bacteria induce the emergence of new organs on plant roots, called nodules, and colonize them. Rhizobia present in nodules reduce dinitrogen into ammonia and provide the plant host with an extra nitrogen source, whereas the plant supplies the microsymbiont cells with different metabolites which that can be used as a carbon source by bacteria.

Symbiotic interactions between rhizobia and plant hosts are very specific, as they require the exchange of numerous molecular signals secreted by rhizobia and by plants. As a result, in most cases, only some microbial species or symbiovars can establish an efficient symbiosis with specific plant species, e.g. clovers can be nodulated only by Rhizobium leguminosarum sv. trifolii and peas can be nodulated by Rhizobium leguminosarum sv. viciae or Rhizobium pisi (Laguerre et al., 2003; Ramirez-Bahena et al., 2008; Marek-Kozaczuk et al., 2017). In turn, some plant species can enter into symbiotic interactions with numerous microsymbiont species. For instance, Mesorbizobium kowhaii Ach-343 and Mesorbizobium japonicum Opo-235 establish symbiosis with plants belonging to two tribes (Galegeae and Trifolieae), i.e. Astragalus sericeocanus, Oxytropis caespitosa, Glycyrrhiza uralensis, Medicago sativa, and Trifolium pratense. Sinorbizobium fredii $\mathrm{HH} 103$ can effectively nodulate Glycine max, Cajanus cajan (pigeon pea), and Glycyrrbiza uralensis (Safranowa et al., 2019; Walker et al., 2020).

Plants have different defense systems preventing colonization of their tissues by all bacteria inhabiting the rhizosphere. Rhizobial microsymbionts are not the only bacteria that can be found in nodules. It seems that root nodules can be a good environment for a wide variety of bacteria. In recent years, a number of new non-rhizobial symbionts with the ability to induce root nodules and fix atmospheric nitrogen have been described. They represent both the alpha-subclass of Proteobacteria, to which most rhizobium species belong, and the beta-subclass of the Proteobacteria group (Dhole \& Shelat, 2018). These include such species as Methylobacterium nodulans, Blastobacter denitrificans, Devosia sp., Ochrobactrum lupini, Phyllobacterium trifolii, Herbaspirillum lustianum, Ralstonia taiwanensis, and Burkholderia cepacian. Representatives of the $\gamma$-subclass of Proteobacteria, as well as Actinobacteria and Firmibacteria, have also been detected in the root nodules (Dhole \& Shelat, 2018). Nodules of various legumes provide an ecological niche for strains representing e.g. Pantoea sp., Pseudomonas sp., Arthrobacter sp., Erwinia sp., Curtobacterium sp., Staphylococcus sp., Bacillus sp., and Paenibacillus sp. (De Meyer et al., 2015; Dhole \& Shelat, 2018). Some studies have shown that bacterial endophytes can help in improving nodulation and nitrogen fixation in legumes through synergistic interactions with rhizobia (De Meyer et al., 2015; Subramanian et al., 2015).

Chamaecytisus albus (white Spanish broom) is a species belonging to the Fabaceae family. This shrub can be found in only one natural habitat near Hrubieszow in South-Eastern Poland (Przemyski \& Piwowarski, 2009). The Polish natural habitat of Chamaecytisus albus is still shrinking, as well as the number of individual plants that can be found in this area; therefore, this plant was classified as "rare, potentially endangered" in 2006 and "critically endangered" in 2016 in the "Polish Red List of Fern and Flowering Plants" (Kaźmierczakowa et al., 2016). Since 1967, Chamaecytisus albus has been grown ex 
situ at the Botanical Garden in Lublin for research and reintroduction purposes (Petrowicz, 1973).

Endophytes of some Genisteae tribe plants were described (Stępkowski et al., 2018), however, bacteria colonizing Chamaecytisus albus roots have never been studied; therefore, the aim of this work was to isolate bacteria present in Chamaecytisus albus roots in a natural habitat and to perform preliminary genetic and metabolic characterization of the isolate collection. This was intended to (a) discriminate between symbionts and endophytes, and (b) indicate isolates with the greatest potential for formulation of a nature-friendly biofertilizer supporting the growth of Chamaecytisus albus in its natural habitat.

\section{MATERIALS AND METHODS}

\section{Isolation of bacterial strains}

Bacteria were isolated from root nodules of Chamaecytisus albus growing near Hrubieszow in the South-Eastern region of Poland $\left(50^{\circ} 48^{\prime} 09^{\prime \prime} \mathrm{N}, 2^{\circ} 53^{\prime} 31^{\prime \prime E}\right)$. Nodules were harvested and surface-sterilized: rinsed several times with sterile water, incubated with $0.1 \% \mathrm{HgCl}_{2}$ for 5 minutes, rinsed several times with sterile water again, incubated with $70 \%$ ethanol for 5 minutes, and finally rinsed several times with sterile water. Sterilized nodules were crushed in a few drops of sterile water in Petri dishes and transferred onto plates with the 79CA medium (Vincent, 1970). The plates were incubated at $28^{\circ} \mathrm{C}$ for 7 days. Collection of 94 isolates (pure cultures) was used in further experiments.

\section{DNA isolation and PCR fingerprinting}

Total genomic DNA was isolated from the cultures of all isolates using the guanidine thiocyanate method (Pitcher et al., 1989). The concentration and purity of isolated DNA were determined using NanoDrop 2000 (Thermo Scientific). Bacterial DNA fingerprints were examined using the BOX-PCR method with the BOX2AR primer (5'-CTCCGGCAAGGCGACGCTGAC-3') (Wdowiak-Wróbel et al., 2017), followed by electrophoresis of PCR products in 1.5\% agarose gel and staining with ethidium bromide. The analysis of amplicon sets was carried out using Bio1D +++ program ver. 11.10 (Vilber-Lourmat). Next, a dendrogram was constructed using the UPGMA method and the Nei and Li coefficients (Nei \& Li, 1979).

\section{Amplification and sequencing of $\operatorname{gyr} B$ and nod $Z$ gene}

The gyrB gene was amplified by PCR with the gyrB343F and gyrB1043R primers according to the procedure described by Naamala and others (Naamala et al., 2016). The nodZ gene of the Chamaecytisus albus isolates was amplified by PCR with the TSnodZ3 and TSnodZ4 primers as described by Moulin et al. (2004). The amplification reactions were carried out with Color Taq PCR Master Mix (EurX) according to the manufacturer's recommendations. The purified amplicons were electrophoresed in $1 \%(\mathrm{w} / \mathrm{v})$ agarose gel. The amplified products were purified with a Clean-up kit (A\&A Biotechnology) and sequenced with the BigDye Terminator Cycle Sequencing kit (Applied Biosystems, USA). All PCR products were commercially sequenced by Genomed (Genomed S.A., Warsaw, Poland). The obtained nucleotide sequences of the gyrB and nodZ genes were compared with the sequences of the reference strains available in GenBank and were aligned using the ClustalX2 software. The phylogenetic trees of all the strains were constructed using the maximum likelihood method, and the bootstrap analysis was based on 1000 resamplings. The MegaX software was used to construct the phylogram for gyrB and nodZ genes. The gyrB nucleotide sequences were deposited in the GenBank database under accession numbers MZ546944 to MZ547037 and the nodZ sequences under MZ547081 to MZ547114.

\section{Phosphate solubilization}

Phosphate solubilization was tested on the Pikovskaya medium (Pikovskaya, 1948) containing calcium triphosphate (TCP). For each isolate, $10 \mu \mathrm{l}$ of bacterial cells suspended in saline $\left(\mathrm{OD}_{550}=0.2\right)$ were dropped onto plates, which were then incubated at $28^{\circ} \mathrm{C}$ for 14 days. After that, the diameter of cleared zones (indicating a positive result) was measured and the solubilization index was calculated (Elias et al., 2016; Wati et al., 2017). The experiment was performed in triplicate. Pseudomonas sp. 267 strain was used as a positive test control, and the negative control was the Pikovskaya medium itself.

\section{Cellulase production}

Cellulase production was determined on a medium with carboxymethylcellulose (CMC) (Buntić et al., 2019). For each isolate, $10 \mu \mathrm{l}$ of bacterial cells suspended in saline $\left(\mathrm{OD}_{550}=0.2\right)$ were dropped onto plates, which were then incubated at $28^{\circ} \mathrm{C}$ for 14 days. After that, the plates were stained with Lugol and Congo Red solutions. The diameter of zones was measured and the cellulolytic index was calculated (Pointing, 1999; Soeka \& Sulistiani, 2019). The experiment was performed in triplicate. Pseudomonas sp. 267 strain was used as a positive control, and the negative control was the CMC medium itself.

\section{Siderophore production}

The production of siderophores was determined on agar plates with the Blue Agar CAS medium containing ChromAzurol S (Louden et al., 2011). For each isolate, $10 \mu \mathrm{l}$ of bacterial cells suspended in saline $\left(\mathrm{OD}_{550}=0.2\right)$ were dropped on plates, which were then incubated at $28^{\circ} \mathrm{C}$ for 7 days. After that, the diameter of zones with changed color (indicating a positive result) was measured. The siderophore index was calculated likewise the solubilization index and the cellulolytic index, comparing the diameter of colonies and discolored zones. The experiment was performed in triplicate. Pseudomonas sp. 267 strain was used as a positive control, and the negative control was the CAS medium itself.

\section{Production of IAA and indole}

The production of IAA and indole was examined using the TMRT medium (Wdowiak-Wróbel \& Małek, 2016). 5-ml aliquots of liquid TMRT were inoculated with $10 \mu \mathrm{l}$ of bacterial cells of the studied isolates suspended in saline $\left(\mathrm{OD}_{550}=0.2\right)$ and incubated for 5 days at $28^{\circ} \mathrm{C}$ with shaking $(170 \mathrm{rpm})$. After that, the bacterial cultures were divided: one half was used for detection of IAA production with $0.01 \mathrm{M} \mathrm{FeCl}_{3}$ in $35 \% \mathrm{HClO}_{4}$ (Wdowiak-Wróbel \& Małek, 2016), and the other one was used for detection of indole production with the Kovacs reagent (MacWilliams, 2009). The experiment was performed in triplicate. The level of IAA and indole production was assessed based on the color of the suspension after the reaction, and the results were recorded using an arbitrary scale (none, low, medium, high, very high). Psendomonas sp. 267 and E. coli sp. K12 strains 
were used as a positive control, and the negative control was the TMRT medium itself.

\section{HCN production}

The production of $\mathrm{HCN}$ was examined using the 79CA medium (Vincent, 1970) with glycine (4.4 g/l). $5-\mathrm{ml}$ aliquots of liquid medium were inoculated with $10 \mu \mathrm{l}$ of bacterial cells of the studied isolates suspended in saline $\left(\mathrm{OD}_{550}=0.2\right)$ and incubated for 5 days at $28^{\circ} \mathrm{C}$ with shaking $(170 \mathrm{rpm})$. The detection of $\mathrm{HCN}$ was performed as described previously (Wati et al., 2017). The experiment was performed in triplicate. The level of $\mathrm{HCN}$ production was assessed based on the color of the paper, and the results were recorded using an arbitrary scale (none, low, medium, high, very high). Psendomonas sp. 267 strain was used as a positive control, and the negative control was the 79CA medium with added glycine.

\section{Plant test}

Chamaecytisus albus seeds were surface-sterilized using concentrated $\mathrm{H}_{2} \mathrm{SO}_{4}$ and sterile water, and then germinated. Seedlings were placed individually on agar slants with nitrogen-free Fahraeus medium (Vincent, 1970). After one week, the seedlings were inoculated with $100 \mu \mathrm{l}$ of bacterial cells suspended in sterile water $\left(\mathrm{OD}_{600}=0.4\right)$. Each isolate was used for inoculation of five plants. The plants were grown in a greenhouse for 12 weeks in test tubes to prevent contamination with other microorganisms. During incubation, the number of root nodules was counted weekly. After 12 weeks, the plants were moved from sterile conditions into pots filled with a sand and soil mixture, and donated to the Botanical Garden in Lublin, Poland.

\section{RESULTS}

The examination of some physiological traits revealed great diversity of the bacterial strains isolated from Chamaecytisus albus nodules (Fig. 1).

The most abundant was cellulase activity, which was identified in 66 isolates. Moreover, a relatively high cellulolytic index was observed in numerous isolates, and the highest values were recorded for the CAN1, KW114, and KW42 isolates (cellulolytic index $=5.64,5.72$, and 6.76 , respectively).

Siderophores were produced by 60 of the tested isolates; however, the siderophore index for most of them was between 1 and 2. The highest siderophore index values were observed for CAN1 and KW23, i.e. 3.00 for both of these isolates.

Phosphate solubilization was not a common trait, as it was found only in 25 isolates. In most cases, the zones observed around bacterial colonies were thin, resulting in values of the phosphate solubilization index between 0.46 and 2. The best results were recorded for the 2012, CAS16, and KW40 isolates (solubilization index $=2.20$, 2.70 and 3.41 , respectively).

Most of the studied isolates were able to synthesize IAA - positive results were found for 58 isolates, and the colorimetric reaction was relatively strong for a large part of this group (i.e. 33 isolates); hence, they can be classified as a "high production" group.

The ability for indole production was less common in the studied collection - only 16 isolates were classified as positive for this trait. Moreover, in most cases, the in-

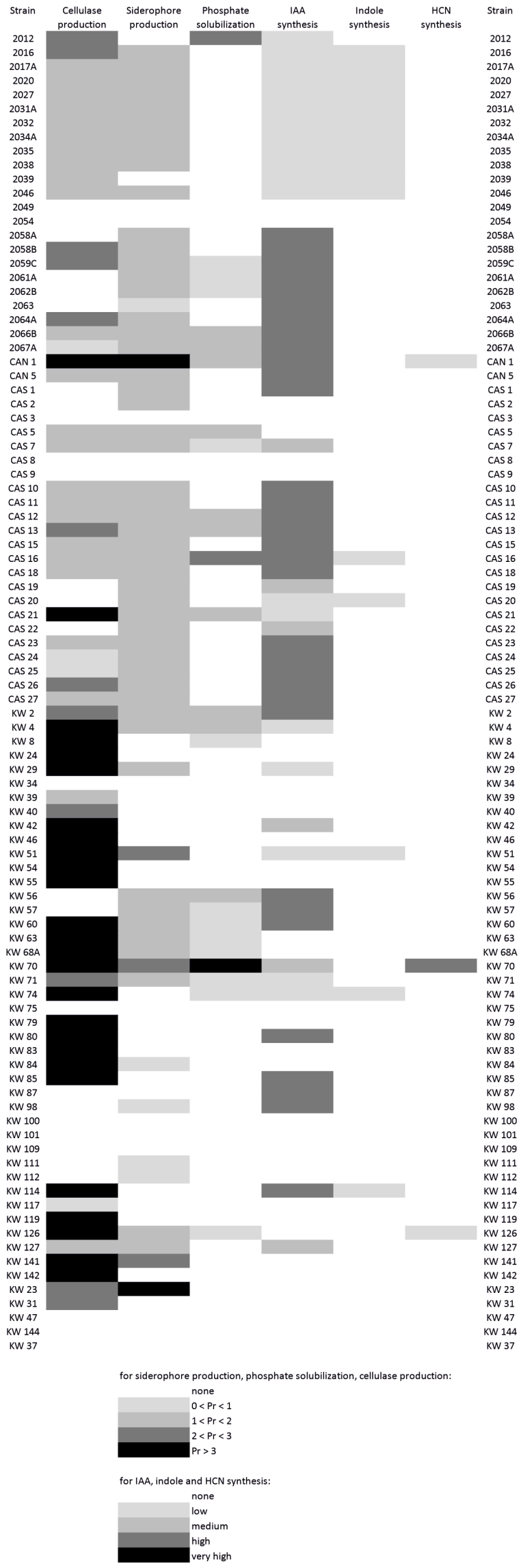

Figure 1. Metabolic traits of isolates originated from Chamaecytisus albus root nodules. 
Table 1. Characterization of the isolates regarding their ability to nodulate Chamaecytisus albus, the presence of the nodZ gene and the species identity based on the gyrB gene.

\begin{tabular}{|c|c|c|c|c|}
\hline Strain & $\begin{array}{l}\text { Number of nodula- } \\
\text { ted plants* }\end{array}$ & $\begin{array}{l}\text { Total number of nodules co- } \\
\text { unted on nodulated plants }\end{array}$ & $\begin{array}{l}\text { Presence of nodZ } \\
\text { gene }\end{array}$ & $\begin{array}{l}\text { Identification to the genus on the } \\
\text { basis of } g y r B \text { gene }\end{array}$ \\
\hline 2054 & 1 & 1 & + & Bradyrhizobium \\
\hline KW8 & 2 & 4 & + & Bradyrhizobium \\
\hline KW23 & 2 & 2 & + & Bradyrhizobium \\
\hline KW24 & 3 & 4 & + & Bradyrhizobium \\
\hline KW31 & 2 & 9 & + & Bradyrhizobium \\
\hline KW34 & 3 & 6 & + & Bradyrhizobium \\
\hline KW37 & 3 & 6 & + & Bradyrhizobium \\
\hline KW39 & 2 & 6 & + & Bradyrhizobium \\
\hline $\mathrm{KW} 40$ & 3 & 5 & + & Bradyrhizobium \\
\hline KW42 & 0 & 0 & + & Bradyrhizobium \\
\hline KW46 & 3 & 5 & + & Bradyrhizobium \\
\hline KW47 & 1 & 1 & + & Bradyrhizobium \\
\hline KW54 & 1 & 1 & + & Bradyrhizobium \\
\hline KW55 & 3 & 7 & + & Bradyrhizobium \\
\hline KW68A & 0 & 0 & + & Bradyrhizobium \\
\hline KW74 & 0 & 0 & + & Bradyrhizobium \\
\hline KW75 & 4 & 10 & + & Bradyrhizobium \\
\hline KW79 & 2 & 2 & + & Bradyrhizobium \\
\hline KW80 & 0 & 0 & + & Bradyrhizobium \\
\hline KW83 & 1 & 2 & + & Bradyrhizobium \\
\hline KW84 & 2 & 3 & + & Bradyrhizobium \\
\hline KW85 & 0 & 0 & + & Bradyrhizobium \\
\hline KW87 & 3 & 8 & + & Bradyrhizobium \\
\hline KW98 & 3 & 6 & + & Bradyrhizobium \\
\hline KW100 & 5 & 6 & + & Bradyrhizobium \\
\hline KW101 & 2 & 3 & + & Bradyrhizobium \\
\hline KW109 & 2 & 2 & + & Bradyrhizobium \\
\hline KW114 & 1 & 2 & + & Bradyrhizobium \\
\hline KW117 & 2 & 3 & + & Bradyrhizobium \\
\hline KW119 & 1 & 1 & + & Bradyrhizobium \\
\hline KW126 & 0 & 0 & + & Bradyrhizobium \\
\hline KW141 & 1 & 4 & + & Bradyrhizobium \\
\hline KW142 & 1 & 1 & + & Bradyrhizobium \\
\hline KW144 & 2 & 7 & + & Bradyrhizobium \\
\hline
\end{tabular}

${ }^{*}$ number of nodulated plants per five tested

tensity of the colorimetric reaction was weak, suggesting a low level of indole production.

Production of HCN was confirmed for only three isolates: CAN1, KW70, and KW126, and the reaction intensity was considerable only for KW70.

As revealed by the plant test, 29 isolates can be considered as Chamaecytisus albus microsymbionts. The other bacterial strains isolated from root nodule tissues were not able to induce the development of nodules (Table 1).

Genome fingerprinting by BOX-PCR also revealed high genetic diversity of the collection, similarly to the phenotypic studies. The molecular typing of the 94 iso- lates from Chamaecytisus albus root nodules, using the BOX2AR primer, generated 3 to 13 bands per isolate, ranging from 79 to $3706 \mathrm{bp}$ (details not shown). In total, 766 amplicons were obtained. The data matrix showing the presence or absence of these bands was analyzed using the Nei and Li coefficient and UPGMA, and the dendrogram displaying the distances between the 94 isolates is shown in Fig. 2. Most of the studied strains formed four groups at a genetic distance of 34\%. Most isolates were found in cluster I with 34 isolates (36\%) and cluster II with 49 isolates $(52 \%)$. This was followed by 7 isolates $(7 \%)$ in group III and 2 isolates $(2 \%)$ in group IV. Two isolates, i.e. CAN1 and CAN5, showed 


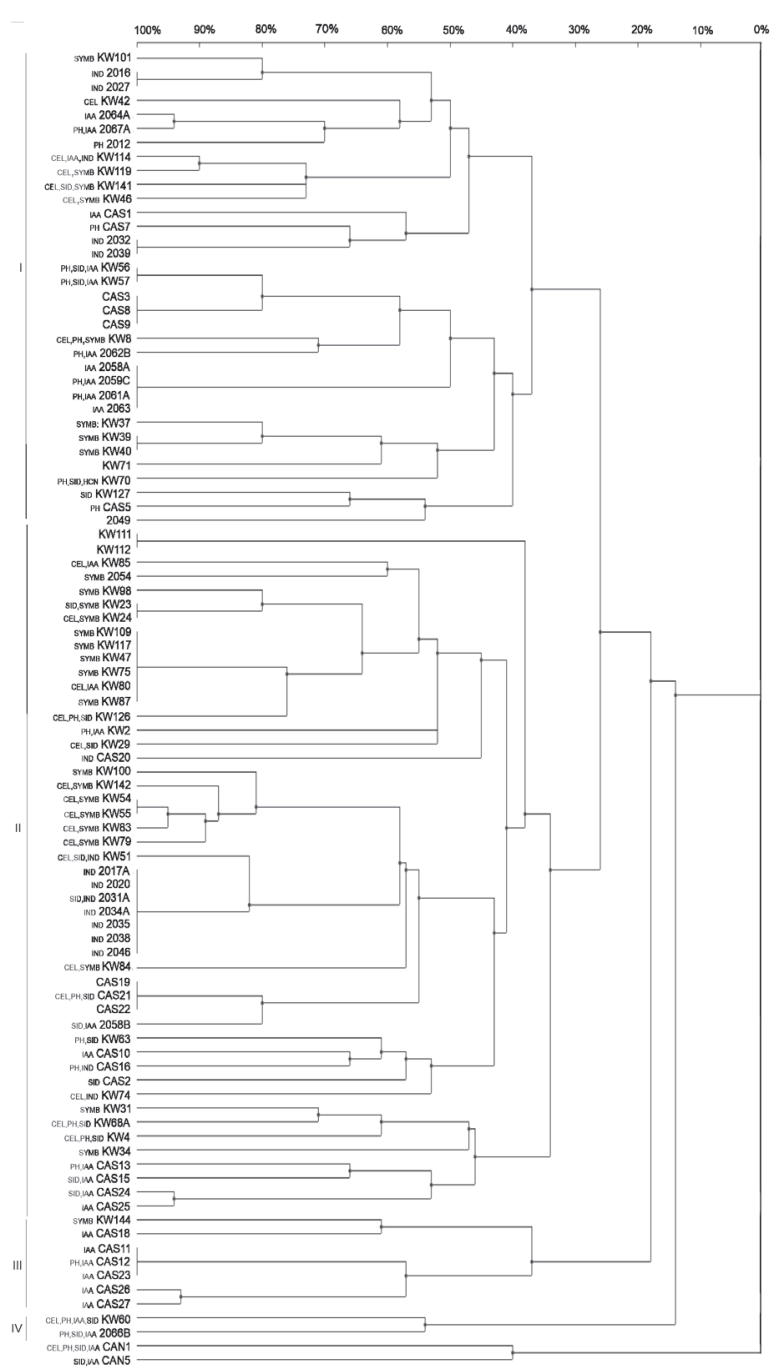

Figure 2. UPGMA dendrogram obtained from BOX-PCR patterns of the Chamaecytisus albus isolates. The scale presents the bacterial genome similarity rate (\%).

SID, PH, CEL - strains with values of the studied traits (siderophore production, phosphate solubilization, cellulase production, respectively) exceeding the 3 rd quartile were marked; IAA, IND, $\mathrm{HCN}$ - strains with values of studied traits (IAA, indole, HCN production, respectively) at the highest level were marked; SYMB strains which nodulated the $C$. albus plants.

no similarity to the other isolates and formed an independent cluster. Interestingly, isolates considered as "symbionts" were not grouped together in one clade. The symbionts were located in clade I in the amount of 9 isolates, in clade III -1 isolate, and most of the isolates clustered in clade II (19 isolates), suggesting that, they may belong to different taxons.

The gyrB gene is an example of a housekeeping gene that is frequently used in classification and identification of different groups of bacteria (Joko et al., 2019). The PCR-amplification of the gyrB gene, which encodes DNA gyrase subunit B, yielded a 584-bp band. The obtained sequences were compared to the gyrB sequences from

Figure 3. The phylogenetic tree of gyrB sequences of the C. albus root nodule isolates and reference strains available in GenBank.

The tree was constructed using the maximum likelihood method. Bootstrap values $\geq 50 \%$ are given at the branching points. GenBank accession numbers are given in parentheses.

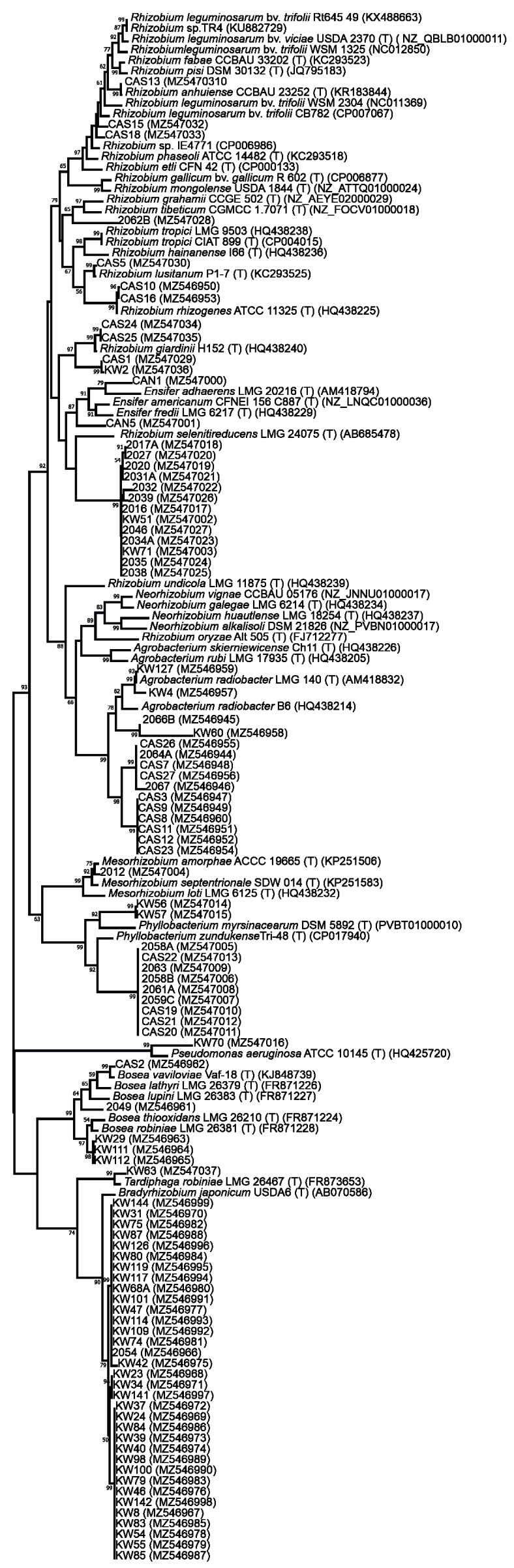


the GenBank database using the BLASTn program. The comparative gyrB gene sequence analysis of Chamaecytisus albus microsymbionts (with $31-100 \%$ gyrB gene sequence similarity to each other) and reference bacteria representing different genera and species showed that the isolates studied belong to the Rhizobium, Bradyrhizobium, Phyllobacterium, Ensifer, Bosea, Tardiphaga and Mesorbizobium genera (Fig. 3). In the phylogenetic tree based on the gyrB sequences, the Chamaecytisus albus root nodule isolates were placed into 8 clusters (Fig. 3). The KW63 isolate was the most similar to Tardiphaga robiniae LMG 26467 (96\% sequence similarity). Among the Chamaecytisus albus microsymbionts, there was one representative of the Pseudomonas genus and one of the Mesorbizobium genus. The next group was composed of CAS2, 2049, KW29, KW111, and KW112 isolates, and the reference strain of Bosea that shared $59-79 \%$ similarities. Two isolates from the root nodules of white Spanish broom represented the Ensifer genus, with a sequence similarity of $68-74 \%$. Representatives of the Bradyrbirobium genus constituted the largest group (Fig. 3). The 34 isolates formed a cluster together with the type strain of B. japonicum that shared sequence similarities of $65-94 \%$ (with a $90 \%$ bootstrap value). The other strains are representatives of the Phyllobacterium (11 isolates) and Rhizobium (22 isolates) genera with sequence similarity of $64-87 \%$ and $68-99 \%$, respectively.

In our study, we analyzed a 430 bp fragment of the nodZ gene to determine the symbiotic relationship of Chamaecytisus albus root nodule isolates with other rhizobia. The nodZ gene was detected in 34 isolates from the root nodules of Chamaecytisus albus, representing the Bradyrbizobium sp. genus (Table 1). It was shown that the nodZ gene sequences of the studied bradyrhizobial strains obtained in this study were grouped with the sequences of Bradyrbizobium reference strains. In the tested isolates, the nodZ genes were identical to each other in the range of $73-99 \%$. Their nucleotide identities ranged from $68 \%$ to $96 \%$ with respect to the nodZ genes of bradyrhizobia. The KW68A, KW80, and KW85 isolates were clustered together and shared 95-96\% sequence homology with Bradyrhizobium jimcamae PAC 68, Bradyrhizobium paxIlaeri LMTR 21, Bradyrbizobium lablabi CCBAU 23086, Bradyrbizobium icense LMTR 13, and Bradyrbizobium valentinum LmjM3 and there is a $65 \%$ bootstrap support in the group I of the nodZ gene phylogenetic tree (Fig. 4). Most isolates (31 isolates) from the root nodules of Chamaecytisus albus formed a monophyletic group on the phylogenetic tree for nodZ with $98 \%$ bootstrap support (Fig. 4).

\section{DISCUSSION}

The genetic and metabolic analyses of the collection of bacterial strains isolated from Chamaecytisus albus nodules has revealed that they can be inhabited by a highly diverse set of bacteria. Some of these isolates are able to induce nodulation; hence, they can be regarded as "true symbionts" and can be called rhizobia. The other isolates should be regarded as endophytes. To date, in addition to rhizobial strains, several other species of bacteria have been isolated from legume nodules without precise determination of their role in the host. In the absence of the ability to induce nodules, they can be regarded as non-rhizobial endophytes (De Meyer et al., 2015; Subramanian et al., 2015). The studies showed that the root nodules of Chamaecytisus albus were comprised of relatively many endophytes in relation to rhizobia. Sixty-five of the 94 bacterial strains tested represented non-nodulating

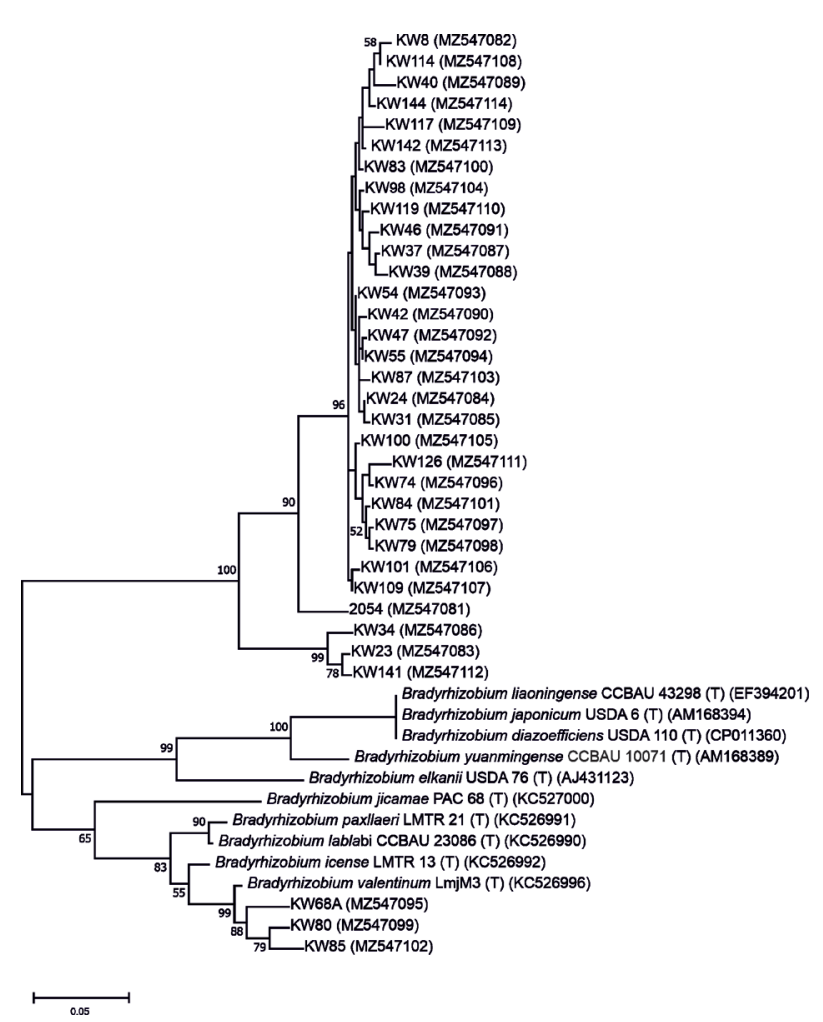

Figure 4. The phylogenetic tree of nodZ sequences of the $C$. albus root nodules isolates and reference strains available in GenBank.

The tree was constructed using the maximum likelihood method. Bootstrap values $\geq 50 \%$ are given at the branching points. GenBank accession numbers are given in parentheses.

strains. This may indicate that the symbiotic rhizobiumlegume plant interaction may have a more complex character than the simple symbiont-host interaction. The presence of endophytes in root nodules can enhance the effect of rhizobia, thus improving the growth and development of plants.

A comparison of the physiological features of rhizobia with those of other endophytes indicates that rhizobia do not have as many potentially beneficial features as endophytes. Most rhizobia have a relatively high cellulase production potential, and it is possible that this facilitates colonization of plant tissues (Robledo et al., 2015). On the other hand, in the group of 29 rhizobial strains, production of siderophores, production of IAA, phosphate solubilization, and indole synthesis were found only in $4,4,1$, and 1 strain, respectively. Only two isolates possessed two potentially beneficial traits other than the cellulase production: KW98 (siderophore and IAA production) and KW114 (IAA and indole synthesis).

The endophytes from the studied collection have different properties. Cellulase production was detected in most cases; however, the cellulolytic indexes of the endophytes were lower than those calculated for the rhizobia. In contrast to the rhizobia, numerous endophytes possessed two or three potentially beneficial traits that can increase plant growth and/or health. The most interesting are isolates CAN1 and KW70, which were able to produce siderophores and IAA, and were also capable of phosphate solubilization.

The results presented here suggest that few isolates derived from our collection can be used as inoculants promoting Chamaecytisus albus growth. Unfortunately, no "universal strain" was found; therefore, further investiga- 
tions should focus on (a) selection of rhizobia with the best symbiotic properties, (b) selection of endosymbionts with the best "supplementary" potential, and (c) relationships between rhizobia, endophytes, and the plant host to choose strains that do not reveal antagonistic behavior and promote plant growth as efficiently as possible. This goal seems to be difficult because Chamaecytisus albus is strictly protected in Poland and, unfortunately, the plant may be damaged during the experiments. However, this work is worth to be done, since it may lead to development of a microbial biofertilizer improving growth of Chamaecytisus albus in the natural habitat and preventing the extinction of this species in the territory of Poland.

Housekeeping genes are widely used in phylogeny to properly delineate closely related species (Martens et al., 2008). One such marker gene is gyrB, whose nucleotide sequence analysis is widely accepted for the determination of phylogenetic relationships of microorganisms. The gyrB gene can be useful in distinguishing between species (Guimarães et al., 2015). It has been shown that this type of analysis may be effective in separating strains as new taxa (Lopez et al., 2021). Molecular characterization of bacterial isolates (based on the sequence of the gyrB gene analysis) derived from nodules of Chamaecytisus albus revealed Bradyrbizobium, Rhizobium, and Phyllobacterium as the predominant genera associated with this wildgrowing protected legume. Some of the tested isolates also represented the Bosea, Ensifer, Tardiphaga, Psendomonas, and Mesorbizobium genera. Additionally, the low degree of similarity of the gyrB gene sequence of the tested isolates to that of the reference strains suggests that they may represent new species. It should be also emphasized that, as far as we know, this is the first description of bacterial strains isolated from Chamaecytisus albus nodules.

The nodZ gene determines the host specificity. The function of the nodZ gene is essential for the biological activity of the lipo-chitose signal molecule (LCO). The nodZ gene product is involved in the addition of a fucosyl residue to the reducing $\mathrm{N}$-acetylglucosamine residue of the host-specific lipochitonoligosaccharide (LCO) Nod factors (Quinto et al., 1997).

It was found that the modification of the Nod factor, for which the nodZ gene product is responsible, is essential for the nodulation process. Additionally, phylogenetic analyses indicate that the nodZ gene was subsequently transferred from the Bradyrbizobium genus to other legume nodule bacteria. The nodZ gene is present in various rhizobial species, e.g. Bradyrbizobium japonicum, Sinorbizobium/Ensifer NGR234, and Azorbizobium caulinodans. It should be emphasized that the nodZ genes in Bradyrbizobium spp. are characterized by high diversity compared to the nodZ genes found in the Mesorbizobium, Ensifer, or Rhizobium genera (Ormeño-Orrillo et al., 2013). Phylogenetic analysis based on the sequence of the nodZ gene showed a common phylogenetic origin of this gene in most strains derived from Chamaecytisus albus. Only three of the tested isolates, i.e. KW68A, KW80, and KW85, formed a common cluster with the Bradyrhizobium valentinum LmjM3 strain, which may suggest that the nodZ gene was transferred from $B$. valentinum to the abovementioned strains.

\section{REFERENCES}

Buntić AV, Milić MD, Stajković-Srbinović OS, Rusulić NV, Delić DI, Mihajlovski KR (2019) Cellulase production by Sinorbizobium meliloti strain 224 using waste tobacco as substrate. Int J Environ Sci Technol 16: 5881-5890. https://doi.org/10.1007/s13762-019-02230-9

De Meyer SED, Beuf KD, Vekeman B, Willems A (2015) A large diversity of non-rhizobial endophytes found in legume root nodules in Flanders (Belgium). Soil Biol \& Biochem 83: 1-11. https://doi. org/10.1016/j.soilbio.2015.01.002

Dhole A, Shelat H (2018) Non-rhizobial endophytes in root nodules. MOJ Biol Med 3: 147-148. https://doi.org/10.15406/mojbm.2018.03.00064

Elias F, Woyessa D, Muleta D (2016) Phosphate solubilization potential of rhizosphere fungi isolated from plants in Jimma Zone, Southwest Ethiopia. Int J Microbiol Article ID 5472601, 1-11. https://doi. org/10.1155/2016/5472601

Guimarães AA, Florentino LA, Almeida KA, Lebbe L., Silva KB, Willems A, Moreira FMS (2015) High diversity of Bradyrbizobium strains isolated from several legume species and land uses in Brasilian tropical ecosystems. Syst Appl Microbiol 38: 433-441. https://doi. org/10.1016/j.syapm.2015.06.006

Kaźmierczakowa R, Bloch-Orłowska J, Celka Z, Cwener A, Dajdok Z, Michalska-Hejduk D, Pawlikowski P, Szczęśniak E, Ziarnek K (2016) Polish Red Data Book of Plants: Pteridophytes and Flowering Plants. Publisher: Institute of Nature Conservation PAS, Cracow (in Polish)

Joko T, Soffan A, Rohman MS (2019) A novel subspecies-specific primer targeting the gyrase B gene for the detection of Pectobacterium carotovoyum subsp. brasiliense. Biodiversitas 20: 3042-3048. https://doi. org/10.13057/biodiv/d201037

Laguerre G, Louvrier P, Allard MR (2003) Compatibility of rhizobial genotypes within natural populations of Rhizobium leguminosarum biovar viciae for nodulation of host legumes. Appl Environ Microbiol 69: 2276-2283. https://doi.org/10.1128/aem.69.4.2276-2283.2003

Lopez BDO, dos Santos Teixeira, Michel DC, Guimarães AA, da Costa AM, Costa JS, de Souza Pereira M, Duarte BLM, de Souza Moreira FM (2021) Genetic and symbiotic characterization of rhizobia nodulating legumes in a mining area in southeast Brazil. Sci Agric 79: 1-12. https://doi.org/10.1590/1678-992X-2020_0238

Louden BC, Haarmann D, Lynne AM (2011) Use of blue agar CAS assay for siderophore detection. J Microbiol Biol Educ 12: 51-53. https://doi.org/10.1128/jmbe.v12i1.249

MacWilliams MP (2012) Indole test protocol. American Society for Microbiology. Washington DC: 1-9

Marek-Kozaczuk M, Wdowiak-Wróbel S, Kalita M, Chernetskyy M, Deryło K, Tchórzewski M, Skorupska A (2017) Host-dependent symbiotic efficiency of Rhizobium leguminosarum bv. trifolii strains isolated from nodules of Trifolium rubens. Antonie van Leeuwenhoek 110: 1729-1744. https://doi.org/10.1007/s10482-017-0922-7

Martens M, Dawyndt P, Coopman R, Gillis M, De Vos P, Willems A (2008) Advantages of multilocus sequence analysis for taxonomic studies: a case study using 10 housekeeping genes in the genus Ensifer (including former Sinorbizobium). Int J Syst Evol Microbiol 58: 200-214. https://doi.org/10./1099/ijs.0.65392-0

Moulin L, Béna G, Boivin-Masson C, Stępkowski T (2004) Phylogenetic analyses of symbiotic nodulation genes support vertical and lateral gene co-transfer within the Bradyrbizobium genus. Mol Phylogen Evol 30: 720-732. https://doi.org/10/1016/S1055-7903(03)00255-0

Naamala J, Jaiswal SK, Dakora FD (2016) Microsymbiont diversity and phylogeny of native bradyrhizobia associated with soybean (Glycine max L. Merr.) nodulation in South African soils. Syst Appl Microbiol 39: 336-344. https://doi.org/10.1016/j.syamp.2016.06.009

Nei M, Li WH (1979) Mathematical model for studying genetic variation in terms of restriction endonucleases. Proc Natl Acad Sci U S A 76: 5269-6273. https://doi.org/10.1073/pnas.76.10.5269

Ormeño-Orrillo E, Servín-Garcidueñas LE, Imperial J, Rey L, Ruiz-Argueso T, Martinez-Romero E (2013) Phylogenetic evidence of the transfer of nodZ and nodL genes from Bradyrbizobium to other rhizobia. Mol Phylogenet Evol 63: 626-630. https://doi.org/10.1016/j. ympev.2013.03.003

Petrowicz M (1973) Badania nad zmiennościa, ekologią i rozmnażaniem Chamaecytisus albus Rothm. Ann UMCS, Sectio C 28: 245-264.

Pikovskaya RI (1948) Mobilization of phosphorus in soil connection with the vital activity of some microbial species. Microbiology 17: 362-370

Pitcher DG, Saunders NA, Owen RJ (1989) Rapid extraction of bacterial genomic DNA with guanidium thiocyanate. Lett Appl Microbiol 8: 151-156. https://doi.org/10.1111/j.1472-765X.1989.tb00262.x

Pointing SB (1999) Qualitative methods for the determination of lignocellulolytic enzyme production by tropical fungi. Fungal Diversity 2: $17-33$

Przemyski A, Piwowarski B (2009) Unclear origin of the new locality of Chamaecytisus albus Rothm. (Hacq.) in Poland: a case of study. Acta Soc Bot Pol 78: 235-239. https://doi.org/10.5586/asbp.2009.030

Quinto C, Wijfjes AHM, Bloemberg GV, Blok-Tip L, López-Lara IM, Lugtenberg BJJ, Thomas-Oates JE, Spaink HP (1997) Bacterial nodulation protein NodZ is a chitin oligosaccharide fucosyltransferase which can also recognize related substrates of animal origin. Pro Natl Acad Sci 94: 4336-4341. htttps://doi.org/10.1073/ pnas.94.9.4336

Ramirez-Bahena MH, García-Fraile P, Peix A, Valverde A, Rivas R, Igual JM, Mateos PF, Martínez-Molina E, Velázquez E (2008) Revision of the taxonomic status of the species Rhizobium leguminosarum (Frank 1879) Frank 1889AL, Rhizobium phaseoli Dangeard 1926AL 
and Rhizobium trifolii Dangeard 1926AL. R. trifolii is a later synonym of $R$. leguminosarum. Reclassification of the strain $R$. leguminosarum DSM 30132 (=NCIMB 11478) as Rhizobium pisi sp. nov. Int J Syst Evol Microbiol 58: 2484-2490. https://doi.org/10.1099/ijs.0.65621-0

Robledo M, Riviera L, Menéndez E, Martinez-Hidalgo P, Rivas R, Velázquez E, Dazzo FB, Martinez-Molina E, Mateos PF (2015) Role of Rhirobium cellulase CelC2 in host root colonization and infection. In Biological Nitrogen Fixation. de Bruijn FJ ed, pp 525-531. https:// doi.org/10.1002/9781119053095.ch53

Safranova V, Belimov A, Sazanova A, Chirak E, Kuznetsova I, Androv E, Pinaev A, Tsyganova A, Seloiverstova E, Kitaeva A, Tsyganov V, Tikhonovich I (2019) Two broad host range rhizobial strains isolated from relict legumes have various complementary effects on symbiotic parameters of co-inoculated plants. Front Microbiol 10: 514. https://doi.org/10.3389/fmicb.2019.00514

Soeka YS, Sulistiani (2019) Production and characterization of cellulase from the newly isolated Bacillus subtilis A8 on rice bran and corncob. IOP Conf Series: Earth and Environmental Science 308 012033: 1-10. https://doi.org/10.1088/1755-1315/308/1/012033

Stępkowski T, Banasiewicz J, Granada CE, Andrews M, Passaglia LMP (2018) Phylogeny and phylogeography of rhizobial symbionts nodulating legumes of the tribe Genisteae. Genes 9: 1-25. https://doi. org/10.3390/genes 9030163
Subramanian P, Kim K, Krishnamoorthy R, Sundaram S, Sa T (2015) Endophytic bacteria improve nodule function and plant nitrogen in soybean on co-inoculation with Bradyrbizobium japonicum MN110. Plant Growth Regul 76: 327-332. https://doi.org/10.1007/s10725014-9993-x

Vincent JM (1970) A manual for the practical study of the root-nodule bacteria. Publisher: Blackwell Scientific Publication Ltd, Oxford

Walker L, Lagunas B, Gifford ML (2020) Determinants of host range specificity in legume-rhizobia symbiosis. Front Microbiol 11: 1-13. https://doi.org/10.3389/fmicb.2020.585749

Wati M, Wati P, Wati L (2017) Screening of rhizobial isolates from Vigna radiata for plant growth promoting traits. Res on Crops 18: 190-195. https://doi.org/10.5958/2348-7542.2017.00032.8

Wdowiak-Wróbel S, Małek W (2016) Properties of Astragalus sp. microsymbionts and their putative role in plant growth promotion. Arch Microbiol 198: 793-801. https://doi.org/10.1007/s00203-0161243-3

Wdowiak-Wróbela S, Mrek-Kozaczuk M, Kalita M, Karaś M, Wójcik M, Małek W (2017) Diversity and plant growth promoting properties of rhizobia isolated from nodules Ononis arvensis. Antonie van Leeuwenhoek 110: 1087-1103. https://doi.org/10.1007/s10482-0170883-x 